Cite this: J. Mater. Chem. B, 2014, 2, 1673

Received 30th October 2013 Accepted 28th January 2014

DOI: 10.1039/c3tb21533d

www.rsc.org/MaterialsB

\title{
Quantifying effects of interactions between polyacrylic acid and chlorhexidine in dicalcium phosphate - forming cements
}

\author{
W. Xia, ${ }^{a}$ M. R. Mohd Razi, ${ }^{\text {bf }}$ P. Ashley, ${ }^{\text {b }}$ E. A. Abou Neel, ${ }^{\text {dae }}$ M. P. Hofmann ${ }^{c}$ \\ and A. M. Young*a
}

The aim of this study was to assess how varying the ratio of aqueous $0.8 \mathrm{M}$ citric acid : $6 \mathrm{M}$ polyacrylic acid (PAA) (3: 0,1 or 3 by weight) affected setting chemistry, mechanical properties and chlorhexidine di-acetate $(\mathrm{CHX})$ release of dicalcium phosphate - forming bone cements. Cement powder included $\beta$-tricalcium phosphate $(\beta-\mathrm{TCP})$ : monocalcium phosphate monohydrate (MCPM): CHX at $1: 1:(0,0.08$ or 0.16$)$ molar ratio. Powder to liquid ratio was fixed at $3: 1$ by weight. Chemical setting kinetics, reactive intermediate formation and final product homogeneity were assessed by ATR FTIR and Raman mapping. Biaxial flexural strength and modulus were determined after 24 hours setting plus 24 hours in water at $37{ }^{\circ} \mathrm{C}$ and analysed using Weibull type equations. $\mathrm{CHX}$ release from $1 \mathrm{~mm}$ thick set discs was assessed over 4 weeks using UV spectroscopy. FTIR demonstrated that $\mathrm{CHX}$ interaction with citric acid inhibited formation of the reactive citrate/dicalcium phosphate intermediate complex that enables delay before snap set. High $\mathrm{CHX}$ additionally increased strength variability. Upon partial citric acid substitution with higher levels of PAA, delay before cement set was maintained. Monetite instead of brushite, however, was formed in conjuction with more stable polyacrylate complexes. These formulations had much improved strength but also greater modulus. $\mathrm{CHX}$ addition and interaction with PAA encouraged greater brushite instead of monetite formation. These complex interactions enabled formulations with high drug and PAA to have improved strength without increase in modulus. They also had low strength variability and better (slower) controlled release of drug. These properties are beneficial for cement use in a range of orthopaedic and dental applications.

\section{Introduction}

Calcium phosphate cements (CPCs) are widely used as bone fillers in orthopaedics. ${ }^{1-3}$ They also, however, have potential as both jaw bone substitutes and tooth root filling materials in dentistry. In these applications, CPCs may provide calcium and phosphate ions for re-mineralisation of new bone or tooth demineralised by periodontal or carious bacteria. In addition, CPCs can provide controlled release of antibacterial agents either by diffusion and/or upon cement degradation. ${ }^{4-7}$

\footnotetext{
${ }^{a}$ Division of Biomaterials and Tissue Engineering, UCL Eastman Dental Institute, 256 Gray's Inn Road, London, WC1X 8LD, UK. E-mail: anne.young@ucl.ac.uk

${ }^{b}$ Department of Paediatric Dentistry, UCL Eastman Dental Institute, 256 Gray's Inn Road, London, WC1X $8 L D$, UK

${ }^{c}$ Biomaterials Unit, School of Dentistsry, Univeristy of Birmingham, Birmingham, B4 $6 N N, U K$

${ }^{d}$ Conservative Dental Sciences Department, Biomaterials Division, Faculty of Dentistry, King Abdulaziz University, Jeddah, Kingdom of Saudi Arabia

${ }^{e}$ Biomaterials Department, Faculty of Dentistry, Tanta University, Egypt

${ }^{f}$ Department of Paediatric Dentistry, Hospital Sultanah Aminah, 80100, Johor Bahru, Johor, Malaysia
}

CPCs are generally either hydroxyapatite (HA) or brushite forming. Brushite (dicalcium phosphate dihydrate) - forming formulations can be produced by mixing mono and tri calcium phosphates (MCPM and TCP) with water. The chemical setting reaction is given by:

$\mathrm{Ca}\left(\mathrm{H}_{2} \mathrm{PO}_{4}\right)_{2} \cdot \mathrm{H}_{2} \mathrm{O}+\beta-\mathrm{Ca}_{3}\left(\mathrm{PO}_{4}\right)_{2}+7 \mathrm{H}_{2} \mathrm{O} \rightarrow 4 \mathrm{CaHPO}_{4} \cdot 2 \mathrm{H}_{2} \mathrm{O}(1)$

Early retardation of this reaction is required to provide sufficient mixing/working time. Subsequent rapid snap set after application, however, is beneficial for preventing leakage from the site of application. In brushite cements, working time may be enhanced through use of calcium chelating molecules such as citric acid. Optimisation of setting retardant levels enables maximisation of powder content, thereby reducing porosity and increasing strength. Too much citric acid, however, has been found to cause formation of monetite (anhydrous dicalcium phosphate) instead of brushite. ${ }^{2}$ As water is not bound in monetite, formation of this dicalcium phosphate effectively decreases the final solid to liquid (or pore) ratio and thereby reduces strength. ${ }^{8}$ 
Despite significant improvement in optimised CPC cement compressive strengths in the past 10 years, relatively few studies have considered tensile or flexural properties. The low values observed for these strengths, however, prevent CPC use in many higher load bearing applications. ${ }^{9}$ Moreover, increase in strength is generally associated with a rise in modulus, brittle fracture and poor resilience. ${ }^{10}$ With brittle CPCs the range of strengths for a given formulation can also be wide.

Many studies have considered release of antibiotics from CPCs. Antibiotic resistance, however, is of growing concern particularly in dental applications. The antibacterial chlorhexidine diacetate $\left[\left(\mathrm{CH}_{2}\right)_{3} \mathrm{NH}(\mathrm{C}(=\mathrm{NH}) \mathrm{NH})_{2} \mathrm{C}_{6} \mathrm{H}_{4} \mathrm{Cl}\right]_{2} \cdot 2 \mathrm{CH}_{3} \mathrm{COOH}$ (CHX) has minimum inhibitory concentrations for many bacteria that are comparable with antibiotics but the reported bacterial resistance is lower. ${ }^{\mathbf{1 1 2}}$ It is widely used in dentistry for plaque control. Commercial examples in which it is employed include Corsodyl $^{\mathrm{TM}}$ and PerioChip ${ }^{\circledR} .^{\mathbf{1 3 , 1 4}}$ Release of chlorhexidine from brushite cement has previously been investigated. ${ }^{5}$ Chlorhexidine and other drug release from CPCs, however, can be too rapid for prolonged benefit. ${ }^{14}$ Antibiotics can additionally affect setting and mechanical properties. ${ }^{4-7}$ Chlorhexidine was previously found to have only minor effects on brushite setting kinetics but its effects on mechanical properties were not reported. ${ }^{5}$

Polyacrylic acid (PAA) has been used in various implantable cements for over 50 years. It is a main component of commercial glass ionomer cements employed for both tooth and bone repair. ${ }^{15,16}$ Early CPC studies demonstrated that PAA can interact with antibiotic gentamicin and slow its release from brushite cements. ${ }^{7}$ PAA has also been shown to enhance the strength of CPC. ${ }^{17}$ The aim of this new study is therefore to address how citric acid replacement by PAA affects setting kinetics, final chemistry, flexural strength and CHX release of a TCP/MCPM cement. It will also cover, if PAA can increase cement flexural strength without enhancing modulus or causing a broadening of strength values.

\section{Materials and methods}

Cements were prepared using aqueous polyacrylic and/or citric acid, mono and tricalcium phosphate and chlorhexidine diacetate powder. FTIR and Raman spectroscopy were used to assess setting kinetics and final composition of set cements respectively. Biaxial flexural strength and modulus were assessed through two-parameter Weibull distribution analysis. CHX release profiles in water were also determined.

\subsection{Materials}

$\beta$-Tricalcium phosphate (TCP) was prepared as previously described $^{\mathbf{1 8 , 1 9}}$ (median particle size of 11 micron). Monocalcium phosphate monohydrate (MCPM) powder (Rhodia, Birmingham, UK) (particle size $62 \mu \mathrm{m}^{20}$ ), chlorhexidine diacetate salt hydrate (CHX) and citric acid powders (ACS grade SigmaAldrich, UK) were employed. 0.8 M ( 15 wt $\%)$ aqueous citric acid solution (CA) was prepared. $6 \mathrm{M}(\sim 43 \mathrm{wt} \%)$ aqueous polyacrylic acid (PAA) solution was obtained from GC America Inc (Fuji IX liquid). MALDI-TOF mass spectrometry indicated a number average PAA molecular weight of $\sim 2100 \mathrm{~g} \mathrm{~mol}^{-1}$.

\subsection{Cement and disc preparation}

Fluid pastes were obtained by mixing powder: liquid in a weight ratio of $3: 1$. Powders contained molar ratios of MCPM : TCP : CHX of $1: 1:(0,0.08$ or 0.16$)$. The higher level of CHX is the maximum that previous studies showed can be included in a basic brushite cement without significantly increasing reaction rate. ${ }^{5}$ Liquids consisted of $0.8 \mathrm{M} \mathrm{CA}: 6 \mathrm{M}$ PAA in weight ratios $3:(0,1$ or 3$)$. Formulations were coded as $\mathrm{C} x \mathrm{P} y$ where $x$ and $y$ are approximate weight percentages of CHX $(0,6$ or $12 \mathrm{wt} \%)$ and PAA $(0,3$ and $6 \mathrm{wt} \%)$ in the cement (see Table 1).

For flexural testing and drug release studies, cement discs of $10 \mathrm{~mm}$ diameter and $1 \mathrm{~mm}$ thickness were prepared using metal rings as moulds. The samples were sealed in the rings using acetate sheet on both sides and left to fully set at $37^{\circ} \mathrm{C}$ for 24 hours before specimen removal.

\subsection{Setting chemistry analysis using FTIR}

Cement setting reactions were assessed using a Perkin Elmer Series 2000 FTIR spectrometer (Beaconsfield, UK). Approximately $0.35 \mathrm{~g}$ of each paste was placed on the diamond of a golden gate ATR attachment (Specac) at $37^{\circ} \mathrm{C}$. Cement spectra were generated between 700 and $4000 \mathrm{~cm}^{-1}$ with a resolution of $8 \mathrm{~cm}^{-1}$. These were collected every $6 \mathrm{~s}$ from within $30 \mathrm{~s}$ from the start of cement mixing for 1 hour and converted into profiles using Timebase software (Perkin Elmer).

Table 1 Cement codes and compositions

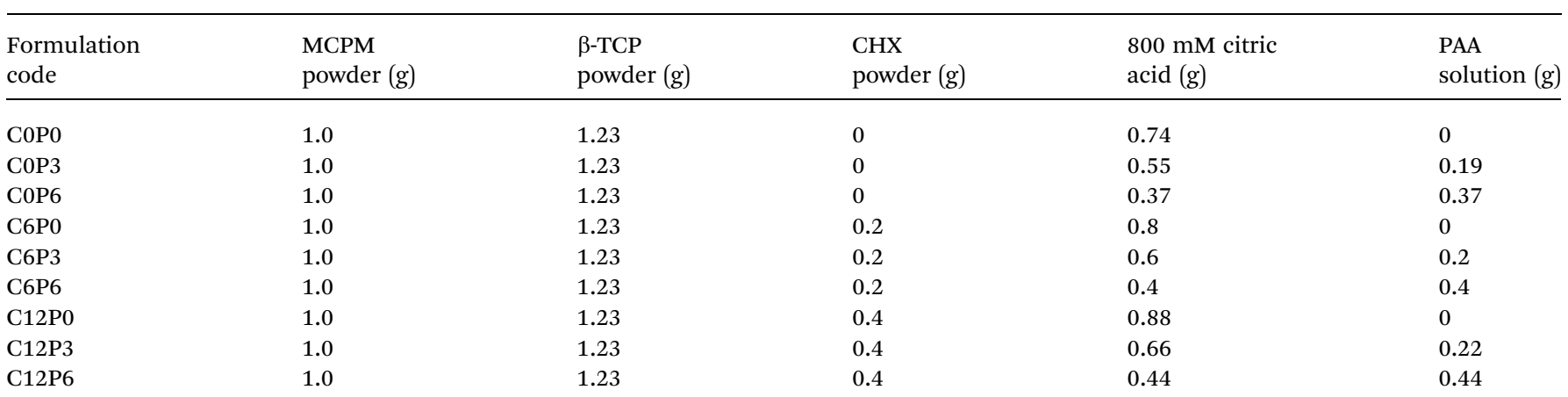


Difference spectra were calculated by subtracting the first spectrum at $100 \mathrm{~s}$ from that at later times. These are characteristic for different chemical reactions and for a simple single reaction with no intermediate products are independent of time. Characteristic difference spectra for setting brushite and glass ionomer cements can be found in ref. 2 and 16 respectively. From absorbance profiles, absorbance change $\Delta A$, maximum absorbance change, $\Delta A_{\max }$, and apparent fractional reaction extent, $\zeta$ were calculated at various wavenumbers. These are defined by ${ }^{8}$

$$
\zeta=\frac{\Delta A}{\Delta A_{\max }}=\frac{A_{t}-A_{0}}{A_{\mathrm{f}}-A_{0}}
$$

$A_{0}, A_{t}$ and $A_{\mathrm{f}}$ are absorbance at time $0, t$ and finally. $A_{0}$ and $A_{\mathrm{f}}$ were calculated by linear extrapolation of early absorbance versus time, or late absorbance versus inverse time, to zero. Additionally, the time for half reaction, $t_{0.5}$ defined as the time at which reaction extent equalled 0.5 , was calculated in seconds.

\subsection{Raman spectra of set cements}

Cements set at $37{ }^{\circ} \mathrm{C}$ were examined using Raman mapping. A LabRam spectrometer (Horiba Jobin Yvon, Stanmore, UK), equipped with a $633 \mathrm{~nm}$ laser, grating set at $1800, \times 50$ objective and wavenumber range of 700 to $1650 \mathrm{~cm}^{-1}$ was used. For each specimen, spectra were obtained in 3 mapping areas. Each area was $50 \times 50 \mu \mathrm{m}$ and spectra were obtained in $10 \mu \mathrm{m}$ steps providing 25 spectra per area. Run time and number were selected to ensure sufficient peak intensity above background and noise. Peak assignments were achieved by comparison with spectra of pure $\beta$-TCP, MCPM, brushite, monetite, CHX and PAA and LabRam software (Horiba Jobin Yvon). ${ }^{5}$ Ratios of different components in a set formulation were estimated from the number of spectra containing peaks for a given chemical divided by the total number of spectra generated.

\subsection{Biaxial flexural properties}

For strength and modulus studies, a "ball on ring" biaxial flexural test method was employed. Twenty discs for each formulation were prepared. Each disc was hydrated in $10 \mathrm{ml}$ distilled water at $37{ }^{\circ} \mathrm{C}$ for 24 hours before testing. Sample thickness $t$, was measured at three different points and averaged. Each sample was then placed on a knife edge ring support (radius $a=4 \mathrm{~mm}$ ) and loaded using a spherical tip in an Instron 4505 Universal Testing Machine. The strength and modulus were calculated using eqn (3) and (4) ${ }^{21}$

$$
\sigma=\frac{P}{t^{2}}\left[(1+\nu)\left(0.485 \ln \left(\frac{a}{t}\right)+0.52\right)+0.48\right]
$$

and

$$
E=\left[\frac{\mathrm{d} P}{\mathrm{~d} \omega}\right]\left[\frac{0.5024 a^{2}}{t^{3}}\right]
$$

where $\sigma$ - strength (MPa), $P$ - force $(\mathrm{N}), \omega$ - central specimen displacement (mm), $a$ - support radius (mm), $t$ - thickness of the disc (mm), $\nu$ - Poisson's ratio and was taken as $0.3,{ }^{22,23} E-$ modulus (GPa).
Strength and modulus distributions were fitted to a Weibull expression: ${ }^{24}$

$$
P_{\mathrm{f}}=1-\exp \left(-\sigma / \sigma_{\theta}\right)^{m}
$$

where $m$ - Weibull shape parameter, $P_{\mathrm{f}}$ - probability of fracture, $\sigma$ - flexural strength or modulus of each specimen, $\sigma_{\theta}-$ Weibull scale parameter.

When $\sigma=\sigma_{\theta}, P_{\mathrm{f}}=63.2 \%$. $P_{\mathrm{f}}$ was defined as $(i-0.5) / n$, where $n$ is the number of specimens and $i$ is the rank of a specimen in a list when strength or modulus are ordered from lowest to highest values. Taking double logs of eqn (5) gives:

$$
\ln \ln \left[1 /\left(1-P_{\mathrm{f}}\right)\right]=m \ln \sigma-m \ln \sigma_{\theta}
$$

Weibull parameters and quality of fit were therefore calculated from the slope and intercept and $R^{2}$ values of linear regression of the left hand side of eqn (6) plotted versus $\ln \sigma$. One-way analysis of variance (ANOVA) and $t$-test at a significance level of $95 \%$ were utilised to identify if properties were significantly different between formulations.

\subsection{Chlorhexidine release}

To quantify CHX release, fully set discs $(10 \mathrm{~mm}$ diameter and $1 \mathrm{~mm}$ thickness) of each composition $(n=3)$ were weighed and immersed in $10 \mathrm{ml}$ of distilled water (at $37^{\circ} \mathrm{C}$ ) within sterile tubes. At time points of 1, 2, 4, 8, 24, 72, 168, 336 and 672 hours the specimens were removed and replaced in fresh distilled water. UV spectra of storage solutions were obtained between 200 and $400 \mathrm{~nm}$ using a Unicam UV 500 spectrometer (Thermo Spectronic, UK). These were compared with calibration graphs created in the same range for solutions of known concentration to ensure $\mathrm{CHX}$ was the only component causing absorbance. The CHX peak at $255 \mathrm{~nm}$ was then used to calculate the cumulative percentage release at a given time from each specimen. ${ }^{5}$ Confidence interval at 95\% for CHX release was calculated from standard deviation (SD) using

$$
\mathrm{CI}=\frac{2 \mathrm{SD}}{\sqrt{n}}
$$

\section{Results}

\subsection{FTIR kinetic investigations: difference spectra}

Example final FTIR difference spectra, obtained by subtracting the spectra at $100 \mathrm{~s}$ from those at $3600 \mathrm{~s}$, are presented in Fig. 1. Their peaks and trough assignments are listed in Table 2. These were, for most samples, consistent with a brushite (dicalcium phosphate dihydrate, DCPD) cement reaction. Brushite cement difference spectra have peaks due to both dicalcium phosphate formation (DCP) (between 800 and $1200 \mathrm{~cm}^{-1}$ ) and water binding (1640 and $3300 \mathrm{~cm}^{-1}$ ). The two exceptions were C0P3 and C0P6. Difference spectra of these two formulations had several peaks consistent with DCP formation but no water binding peaks or characteristic DCPD peak at $985 \mathrm{~cm}^{-1}$. This suggests monetite instead of brushite formation. These exceptions also gave broad difference spectra bands (840, 1380 and 


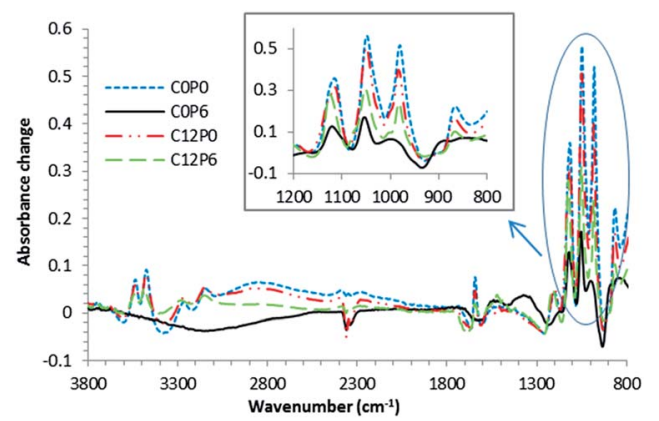

Fig. 1 Example FTIR difference spectra at $3600 \mathrm{~s}$ for cements setting at $37^{\circ} \mathrm{C}$

Table 2 Assignment of FTIR difference spectra peaks and troughs

\begin{tabular}{|c|c|c|c|}
\hline $\begin{array}{l}\text { Wavenumber } \\
\left(\mathrm{cm}^{-1}\right)\end{array}$ & Peak/trough & Dominant cause & $\begin{array}{l}\text { Dominant } \\
\text { assignments }\end{array}$ \\
\hline 3540 & $\begin{array}{l}\text { Peak } \\
\text { sharpening }\end{array}$ & $\begin{array}{l}\text { Water binding in } \\
\text { DCPD }\end{array}$ & O-H stretch \\
\hline 3480 & $\begin{array}{l}\text { Peak } \\
\text { sharpening }\end{array}$ & $\begin{array}{l}\text { Water binding in } \\
\text { DCPD }\end{array}$ & $\mathrm{O}-\mathrm{H}$ stretch \\
\hline 3280 & $\begin{array}{l}\text { Peak } \\
\text { sharpening }\end{array}$ & $\begin{array}{l}\text { Water binding in } \\
\text { DCPD }\end{array}$ & O-H stretch \\
\hline 3160 & $\begin{array}{l}\text { Peak } \\
\text { sharpening }\end{array}$ & $\begin{array}{l}\text { Water binding in } \\
\text { DCPD }\end{array}$ & O-H stretch \\
\hline 3000 & Broad trough & Acid neutralisation & $\mathrm{O}-\mathrm{H}$ loss \\
\hline 1650 & $\begin{array}{l}\text { Peak } \\
\text { sharpening }\end{array}$ & $\begin{array}{l}\text { Water binding in } \\
\text { DCPD }\end{array}$ & $\mathrm{O}-\mathrm{H}$ stretch \\
\hline 1570 & Broad band & Citrate & $\begin{array}{l}\text { Asymmetric } \mathrm{COO} \\
\text { stretch }\end{array}$ \\
\hline 1520 & Broad band & Polyacrylate & $\begin{array}{l}\text { Asymmetric COO } \\
\text { stretch }\end{array}$ \\
\hline 1440 & Broad band & Citrate & $\begin{array}{l}\text { Symmetric COO } \\
\text { stretch }\end{array}$ \\
\hline 1380 & Broad band & Polyacrylate & $\begin{array}{l}\text { Symmetric COO } \\
\text { stretch }\end{array}$ \\
\hline 1250 & Trough & Acid neutralisation & $\mathrm{C}-\mathrm{O}$ stretch loss \\
\hline 1230 & Trough & MCPM loss & P-O stretch loss \\
\hline 1210 & Sharp peak & DCP & $\mathrm{P}-\mathrm{O}$ stretch \\
\hline 1125 & Sharp peak & DCP & $\mathrm{P}-\mathrm{O}$ stretch \\
\hline 1070 & Sharp trough & MCPM loss & $\mathrm{P}-\mathrm{O}$ stretch loss \\
\hline 1055 & Sharp peak & DCP & $\mathrm{P}-\mathrm{O}$ stretch \\
\hline 1010 & Sharp trough & TCP loss & $\mathrm{P}-\mathrm{O}$ stretch loss \\
\hline 985 & Sharp peak & DCPD & $\mathrm{P}-\mathrm{O}$ stretch \\
\hline 960 & Trough & MCPM loss & P-O stretch \\
\hline 880 & Broad band & Citrate & $\mathrm{COO}$ \\
\hline 870 & Sharp peak & DCP & $\mathrm{P}-\mathrm{O}(\mathrm{H})$ \\
\hline 840 & Broad band & Polyacrylate & $\mathrm{COO}$ \\
\hline 780 & Broad band & DCPD & Water libration \\
\hline
\end{tabular}

$1520 \mathrm{~cm}^{-1}$ ) typically observed upon neutralisation of polyacrylic acid in a glass ionomer cement.

\subsection{FTIR kinetic investigations: absorbance profiles}

$\Delta A_{\max }$ values calculated using absorbance changes at 1050 and $980 \mathrm{~cm}^{-1}$ are provided for all formulations in Fig. 2a. Repetition indicated good reproducibility for all samples except C12P0. For most formulations, $\Delta A_{\max }$ values were roughly comparable at
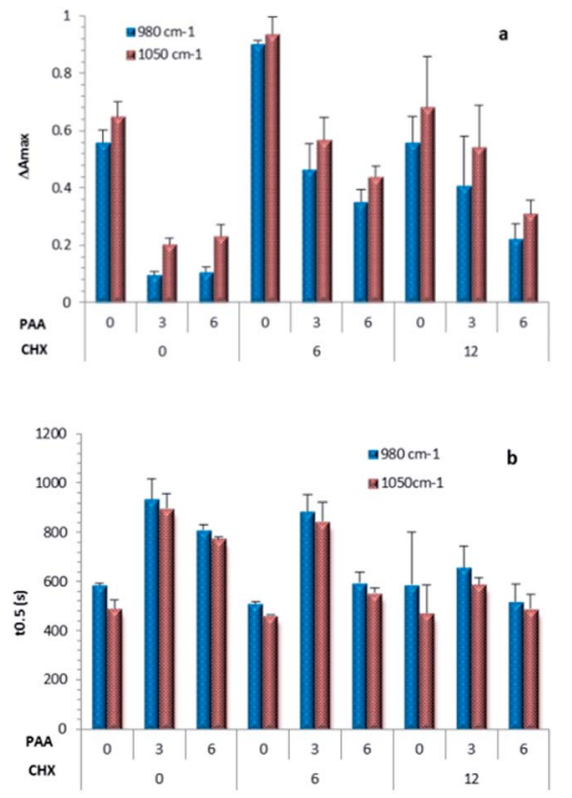

Fig. 2 FTIR parameters obtained using profiles at $980 \mathrm{~cm}^{-1}$ and $1050 \mathrm{~cm}^{-1}$ for cements with different PAA and CHX weight percentages (error bars indicate difference upon repetition). (a): Maximum absorbance change, $\Delta A_{\max }$ (b): time for half maximum absorbance change, $t_{0.5}(\mathrm{~s})$.

these two wavenumbers but both declined upon increasing PAA. $\Delta A_{\max }$ values for C0P3 and C0P6, however, were particularly low. They were also anomalous in that the absorbance change at $1050 \mathrm{~cm}^{-1}$ was approximately double that at $980 \mathrm{~cm}^{-1}$ instead of comparable. This was consistent with formation of monetite instead of brushite.

Time for half reaction $t_{0.5}$, calculated from profiles at $1050 \mathrm{~cm}^{-1}$ gave comparable results to those from $980 \mathrm{~cm}^{-1}$ profiles (see Fig. 2b). Addition of CHX had negligible effect on time of half reaction when PAA was absent, but caused up to $30 \%$ reduction of $t_{0.5}$ when polymer was present. Moreover, partial replacement of citric acid by a more concentrated PAA solution enabled retardation of the setting reaction to be maintained and in some cases (particularly COP3, COP6 and C6P3) enhanced.

Fig. 3a provides examples of reaction extent versus normalised time. These show that with all formulations there was a delay before rapid reaction. Citric acid replacement by PAA had negligible effect on the shape of these profiles and the inhibition period was approximately half the half-life. Addition of CHX, however, could cause the reaction to be less sharp and the delay before reaction to be a smaller fraction of the reaction half-life.

For most samples, during early stages of the reaction a small temporary increase in absorbance at $1400 \mathrm{~cm}^{-1}$, consistent with the formation of reactive intermediate citrate complexes, was observed (see for example Fig. 3b). Addition of CHX decreased the time over which this change was observed. Conversely with $\mathrm{COP} 3$ and C0P6, absorbance increase at $1400 \mathrm{~cm}^{-1}$ was not lost during later stages of the reaction. This suggests formation of a more stable calcium polyacrylate complex. Comparison of 

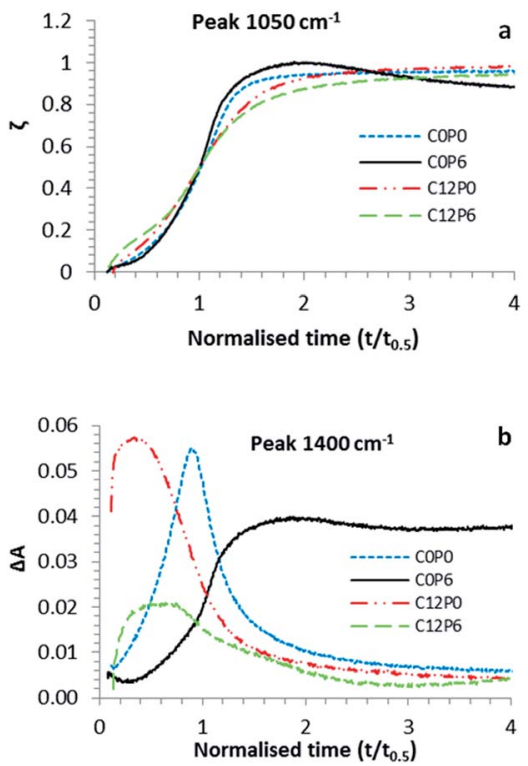

Fig. 3 (a) Reaction extent $\zeta$ at $1050 \mathrm{~cm}^{-1}$ and (b) absorbance change $\Delta A$ at $1400 \mathrm{~cm}^{-1}$. In both cases $t_{0.5}$ was calculated from the $1050 \mathrm{~cm}^{-1}$ absorbance profile.

Fig. 3a and b indicates polyacrylate complex forms at the same time as monetite precipitation. Conversely the reactive intermediate citrate complexes form before brushite precipitation.

\subsection{Raman spectroscopy}

Average Raman spectra. Average Raman spectra of selected formulations are illustrated in Fig. 4 and peak assignments listed in Table 3. Average spectra of most formulations gave a strong distinctive brushite peak at $987 \mathrm{~cm}^{-1}$. In contrast, with C0P3 and C0P6 this peak was much broadened and more comparable with a monetite Raman spectrum. Furthermore, in C0P6 there were organic polymer peaks around $1400-1500 \mathrm{~cm}^{-1}$ consistent with calcium polyacrylate. In $\mathrm{CHX}$ containing formulations, any polymer peaks were masked in average spectra by the various sharp, strong and overlapping peaks of the drug.

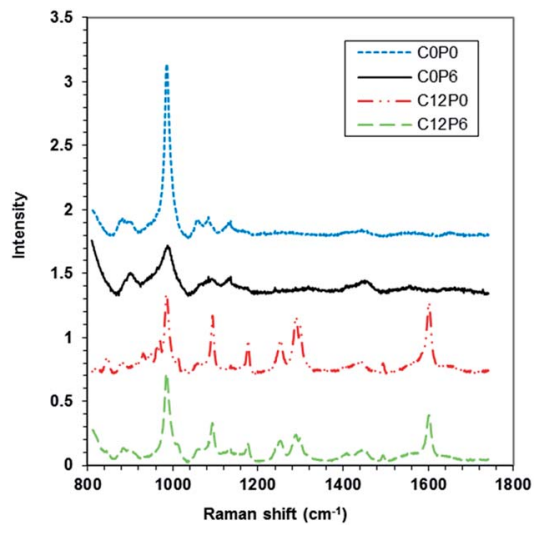

Fig. 4 Average Raman spectra of set cements.
Table 3 Assignment of Raman spectra peaks

\begin{tabular}{lll}
\hline Wavenumber $\left(\mathrm{cm}^{-1}\right)$ & Component & Peak type \\
\hline 890 & DCPD & Sharp weak singlet \\
900 & DCP & Broad weak peak \\
906 & MCPM & Sharp strong doublet \\
955 & TCP & Sharp strong doublet \\
990 & DCPD & Sharp strong singlet \\
990 & DCP & Broad weak peak \\
1095 & CHX solid & Sharp strong singlet \\
1180 & CHX solid & Sharp strong singlet \\
1250 & CHX solid & Sharp strong singlet \\
1290 & CHX solid & Sharp strong doublet \\
1600 & CHX solid & Sharp strong singlet \\
& & \\
\hline
\end{tabular}

Raman mapping. Raman mapping analysis of set cements indicated $>90 \%$ conversion of MCPM and TCP in all formulations except C6P0 and C12P0 which had 10 and 25\% TCP remaining respectively. C0P0, C6P0, C12P0 and $\mathrm{C} 12 \mathrm{P} 3$ contained brushite but no monetite. Conversely, COP3 and C0P6 contained monetite but no brushite. The ratio of brushite : monetite decreased in the order C6P3 (3:3) < C12P6 (2:3) $<$ C6P6 (1:3). In other words, polymer encourages monetite but CHX brushite formation.

\subsection{Flexural properties of cements}

Probability of fracture was plotted versus biaxial strength (Fig. 5) and associated Weibull parameters calculated (Table 4) for selected formulations. The high $R^{2}$ values indicated good agreement

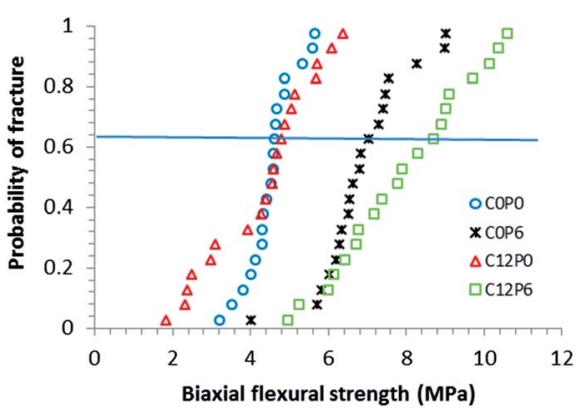

Fig. 5 Probability of fracture versus biaxial flexural strength of selected cements. Line indicates $\sigma_{\theta}$.

Table 4 Weibull scale $\sigma_{\theta}$ and shape $m$ parameters obtained upon fitting eqn (6) to biaxial flexural strength and modulus data

\begin{tabular}{llllll}
\hline & $\begin{array}{l}\text { Weibull } \\
\text { parameters }\end{array}$ & C0P0 & C0P6 & C12P0 & C12P6 \\
\hline Flexural strength (MPa) & $\sigma_{\theta}$ & 4.8 & 7.3 & 4.8 & 8.5 \\
& $m$ & 8.8 & 6.8 & 3.4 & 5.5 \\
& $R^{2}$ & 0.96 & 0.93 & 0.95 & 0.96 \\
Flexural modulus (GPa) & $\sigma_{\theta}$ & 0.45 & 0.63 & 0.42 & 0.49 \\
& $m$ & 4.7 & 3.9 & 1.9 & 4.4 \\
& $R^{2}$ & 0.91 & 0.96 & 0.84 & 0.93
\end{tabular}




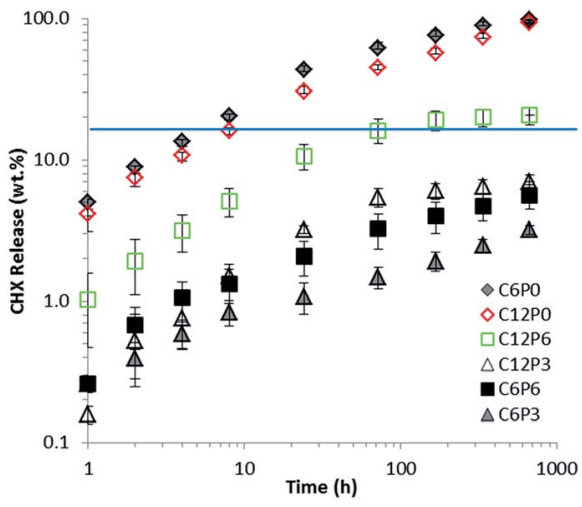

Fig. 6 Cumulative $\mathrm{CHX}$ release from cements in water (note: double $\log$ scale).

between the theoretical expression and strength data for all materials. The Weibull strength scale parameter, $\sigma_{\theta}$, increased significantly $(p<0.05)$ upon addition of PAA but was not affected by $\mathrm{CHX}$. Addition of $\mathrm{CHX}$ also reduced the shape parameter, $m$, indicating a broadened distribution of strengths. The combination of PAA with CHX in C12P6 could partially overcome this problem.

$R^{2}$ values indicated the Weibull expression fitted modulus data of C12P0 less well (see Table 4). As the modulus shape parameter was also particularly low for C12P0 it is likely that these samples were less homogeneous. Addition of PAA alone significantly $(p<0.05)$ increased the modulus but with C12P6 lower modulus and higher shape parameter (i.e. better homogeneity) were maintained.

\subsection{CHX release from cements}

The CHX release profiles in water are provided in Fig. 6. Release rate from $\mathrm{C} 6 \mathrm{P0}$ and $\mathrm{C} 12 \mathrm{P} 0$ without polymer in the first 72 hours was $>50 \%$ and as expected for a rapid diffusion controlled process. By 672 hours (28 days) all the CHX had been released. Formulations with PAA have some release at short times but much of the drug remains trapped consistent with strong interaction between CHX and PAA. C12P6 releases more CHX than other formulations with both PAA and drug. Neither this formulation nor $\mathrm{C6P} 3$ exhibited significant release after 72 hours. For the other formulations (C6P6 and C6P3) continuing release was detectable over 672 hours (28 days) but this was continually slowing. Note - both axes in Fig. 6 were plotted in logarithmic scale to illustrate full range of data for a prolonged period of time.

\section{Discussion}

This study has quantified the effects of partial substitution of $0.8 \mathrm{M}$ citric acid by $6 \mathrm{M}$ PAA and varying CHX levels on setting rates, final composition, mechanical properties, and release kinetics of $\mathrm{CHX}$ from a dicalcium phosphate forming bone cement. Equimolar MCPM : TCP was used as required by eqn (1) for complete reaction. The powder to liquid ratio was close to the highest level possible whilst achieving a fluid paste to maximize strength. The level of citric acid was based upon the amount previous studies have shown are required to ensure sufficient delay for clinical placement before set and optimal mechanical properties. ${ }^{2} 6 \mathrm{M}$ PAA was close to the aqueous solubility limit of this acid but was sufficient to have comparable effect on setting to $0.8 \mathrm{M}$ citric acid. The molecular weight of this PAA was kept low as preliminary studies showed higher molecular weight polymers were less water soluble and unable to act as effective setting retardants.

\subsection{Setting kinetics and final chemistry}

Setting rates of the control brushite cements (COP0) in this study were comparable with those observed previously. ${ }^{5}$ In the controls, citric acid acted as a retardant by chelating with calcium. This interaction provided a period of restricted reaction upon initial mixing and is required for ease of clinical placement. FTIR has previously demonstrated early formation of citric acid/dicalcium phosphate complexes in brushite cements. $^{2}$ These species, however, are reactive intermediates and difficult to detect unless the citric acid concentration is high. High CHX concentrations in both previous work ${ }^{5}$ and this new study reduced the inhibition periods possibly due to its interacting with the citric acid retardants. This new study has also demonstrated CHX can detrimentally broaden the setting time. Raman mapping also confirmed CHX could prevent full conversion of TCP presumably by reducing acidity.

The above studies demonstrate that citric acid $(0.8 \mathrm{M})$ has to be replaced by polyacrylic acid of much higher concentration (6 M) to provide comparable working times particularly with higher levels of CHX also present. Higher PAA concentration may be required due to slower diffusion of the larger polymeric molecules. This would additionally explain why PAA of greater molecular weight could not retard the setting reaction (data not shown). The simultaneous formation of monetite and calcium polyacrylate peaks in FTIR studies of C0P3 and C0P6 suggests these products may form a stable complex together. The greater complex stability compared within C0P0 may be a consequence of the higher levels of PAA compared with citric acid. Additionally, however, the large number of chelating groups per molecule on PAA would inhibit breakdown of the complexes once formed. Interaction between PAA and CHX reduced the formation of these stable complexes enabling brushite to form instead of monetite.

In the cements $\mathrm{C} x \mathrm{P} y$ the ratio of MCPM : TCP was fixed at 1 : 1. Eqn (1) indicates 1 mole of MCPM and TCP will give 4 moles of brushite but this will require 7 moles of water. Relative to MCPM, average moles of citric acid were $0.16,0.12$ or 0.08 , PAA $0,0.3$ or 0.6 and water 10,9 or 8 for $y=0,3$ or 6 respectively. Trivalent citric acid at its highest level $(0.16$ moles per mole MCPM) would require 0.24 moles of divalent calcium to form citrate. PAA at its highest level (0.6 moles per mole MCPM) requires 0.3 moles of calcium to enable full calcium polyacrylate formation. The maximum levels of calcium required to form citrate or polyacrylate salts would therefore be less than $10 \%$ of that in any of the cements ( 4 moles Ca per mole MCPM). These acids are therefore not at sufficient levels to ultimately inhibit dicalcium phosphate precipitation. 
In all the cements there is a slight excess of water for brushite formation. For calcium polyacrylate to also form, previous studies on glass ionomer cements have suggested a minimum of 5 moles of water per mole of PAA are required.$^{15}$ In C0P6, therefore more than 3 moles of water might be required to enable PAA to be fully neutralised leaving less than 5 moles which is insufficient for full brushite formation. This could explain formation of monetite.

Moles of CHX relative to MCPM were $0,0.08$ and 0.16 for $x=$ 0, 6 and 12 respectively. Therefore, as CHX is dibasic, in C12P3 the ratio of acidic PAA to basic CHX groups will be $0.30: 0.32$. If these components fully interact without binding water, this would explain why only brushite and no monetite form. This would also explain why in C6P3, where CHX is halved, approximately equal brushite and monetite are formed. In C6P6, with both CHX halved and PAA doubled the level of monetite is 3 times that of brushite. With C12P6 there was slightly more monetite than brushite which might suggest that not all the CHX in this case has interacted with PAA. This could help explain higher percentage $\mathrm{CHX}$ release in this formulation compared with the other PAA containing cements.

\subsection{Strength and modulus}

The theory behind the Weibull expression is based on the premise that specimen-to-specimen variability of strength is an intrinsic property of the cement, reflecting its flaw population. A material under load may break from a sharp flaw but not from micro-cracks or large pores. Each flaw type has its own distribution. Poor fitting of a simple Weibull expression can be indicative of fracture resulting from multiple flaw types. ${ }^{24}$ As the Weibull equation described fits the strength distributions well in the above cements, it suggests that only one type of flaw is primarily responsible for material failure. The increase in strength with PAA addition (COP6) may be a consequence of polymer/monetite complex formation. Usually formation of monetite is associated with a decrease in strength due to greater porosity and less binding of water in the cement structure. ${ }^{8}$ In this study, however, the polymer is occupying the pores and binding the water. In C12P6 the polymer may again be filling holes but greater brushite formation instead of entirely monetite could further be enhancing the strength.

The broadened strength distribution upon adding $\mathrm{CHX}$ without PAA suggests that the size distribution of flaws was widened. This could be a consequence of reduced TCP conversion and poorer mixing/larger more loosely connected crystals due to faster setting. ${ }^{25}$ Furthermore, fast $\mathrm{CHX}$ release could have increased the number of flaws. Moreover, the inability of the Weibull equation to fit modulus data provides further evidence for poor material homogeneity in $\mathrm{C} 12 \mathrm{P} 0$.

The highest compressive strength reported for brushite cements has been $53 \mathrm{MPa} .{ }^{26}$ Tensile strengths however are an order of magnitude lower and further reduced upon cement placement in water. ${ }^{25}$ Flexural strengths are generally more comparable with tensile than compressive strengths. The flexural strengths obtained in this study, particularly with high PAA, are therefore greater than expected from previous work.
The combination of PAA and CHX also beneficially reduces modulus whilst enabling strength maintenance which will increase resilience (area under stress-strain curve).

To enable CE marking of new materials, expensive in vitro and in vivo studies demonstrating benefit are required. Alternatively, sufficient evidence of previous application of similar materials/ material components in man is required. TCP/MCPM cements have been commercialised by various companies (e.g. ChronOs inject ${ }^{\circledR}$, PD VitalOs $\left.{ }^{\circledR}\right)$ for bone filling due to their injectability, biocompatibility degradability and transformation into brushite and then hydroxyapatite in vivo. ${ }^{25,31,32}$ Additionally, although PAA has been commercially applied more in dental applications it has also been employed previously in bone repair. ${ }^{33}$

A further potential application for the new materials is bone fracture stabilisation. A recent in vivo study showed, however, that the basic brushite cement described in this paper, may be too rigid for this application. Production of more flexible cement, by total replacement of the aqueous phase of the brushite cement with a polymer, solved this issue. ${ }^{32}$ Furthermore, the study suggested that formation of polyacidic groups (as in polyacrylic acid) could enable "self-repair" of the cement-bone interface as the bone remodels. ${ }^{32}$

\subsection{Drug release}

Raman and UV spectroscopy respectively, confirmed that CHX was entrapped within and subsequently released from the brushite cements without change in chemical structure. CHX is known to be effective under acidic conditions in the mouth. The presence of citric or polyacrylic acid was therefore not expected to detrimentally affect the action of this antibacterial. A further advantage of this drug is its ability to bind to oral tissues enabling more prolonged benefit. ${ }^{\mathbf{1 4}}$

CHX release from formulations without PAA (C6P0 and $\mathrm{C} 12 \mathrm{P} 0$ ) was rapid and comparable with previous studies. ${ }^{27}$ Linear release versus square root of time and none dependence upon concentration is as expected upon diffusion controlled drug release from a porous cement. Conversely, CHX release from formulations C6P3, C6P6 and C12P3 was severely inhibited and possibly, for some applications, too much to provide early antibacterial action. With C12P6, however, the moderate early CHX release could be more beneficial. Competition between $\mathrm{CHX}$ and brushite for complexation with PAA would explain the complex dependence of CHX release upon both cement composition and time. The release of CHX from $\mathrm{C} 12 \mathrm{P} 6$ at later times is limited. It should be noted, however, that brushite cements degrade more rapidly in vivo than in vitro due to the action of cells and enzymes. ${ }^{28-30}$ Later time release of CHX is likely therefore to be faster in vivo as the surrounding brushite matrix is lost.

Further potential applications of the new cements are for treatment of perioimplantitis and periodontal disease. In both, bacteria cause recession of the jaw bone. Perioimplantitis is a growing problem that is difficult to treat and results in loosing of tooth implants. The new antibacterial brushite cements could be injected around the implant, treat the disease and provide ions to help the jaw repair. One commercial product for periodontal disease is PerioChip®. This contains 37 vol\% $\mathrm{CHX}$ in a degradable polymer film. One problem, however, is 
difficulty in placement and movement from the site of application. An in vivo study showed this material releases approximately $40 \%$ of its CHX within $24 \mathrm{~h}$. The remainder is released over the next 7 days. ${ }^{14}$ Long term antibacterial action is therefore limited. Furthermore, the concentration of drug initially found in the periodontal pocket $(\sim 1000 \mathrm{ppm})$ is much higher than minimum inhibitory concentrations (MIC) for periodontal bacterial and therefore in excess of what is required.

In comparison, the injectability of the above new brushite cements makes them easier to place and after set, less likely to move. As the brushite cement density is $\sim 2.2 \mathrm{~g} \mathrm{~cm}^{-3}$, those with high CHX contain $\sim 27$ vol\% of this drug. The above new release studies therefore suggest that C12P6 of comparable dimensions will release sufficient CHX in the first 24 hours to provide levels of antibacterial approximately 6 times lower than PerioChip®. This should be sufficient for effective early antibacterial action. In vivo, greater dissolution of C12P6 should enable higher levels of drug to be released than observed in water. This would help maintenance of drug concentration at higher levels than with PerioChip ${ }^{\circledR}$ at later times provided the drug is not washed out of the periodontal pocket too quickly. The level of wash out unfortunately increases as the level of disease progresses. For more extensive disease, more of the material would therefore need to be employed. A further advantage of the brushite cements, however, is that they would additionally provide calcium and phosphate ions to aid regrowth of the jaw bone.

\section{Conclusions}

6 M PAA can partially replace $0.8 \mathrm{M}$ citric acid as a setting retardant for the above dicalcium phosphate - forming cements. These PAA levels can cause monetite instead of brushite precipitation and formation of stable polyacrylate complexes. CHX interaction with citric acid or PAA can reduce the sharpness of the setting reaction. CHX can also prevent full reaction of TCP and through reducing homogeneity broaden the range of cement flexural strengths. PAA addition reduced this problem. CHX interaction with PAA also encouraged brushite instead of monetite formation. These interactions enabled the C12P6 formulation to have relatively low modulus, higher average strength, and more controlled release of CHX.

\section{Acknowledgements}

We acknowledge EPSRC (project EP/I022341/1), Davis Schottlander \& Davis Ltd, and Ministry of Health, Malaysia for financial funding of the project.

\section{References}

1 M. Bohner, U. Gbureck and J. E. Barralet, Biomaterials, 2005, 26, 6423-6429.

2 M. P. Hofmann, A. M. Young, U. Gbureck, S. N. Nazhat and J. E. Barralet, J. Mater. Chem., 2006, 16, 3199-3206.

3 M. Bohner, Injury, 2000, 31, D37-D47.

4 M. P. Ginebra, T. Traykova and J. A. Planell, J. Controlled Release, 2006, 113, 102-110.
5 A. M. Young, P. Y. Ng, U. Gbureck, S. N. Nazhat, J. E. Barralet and M. P. Hofmann, Acta Biomater., 2008, 4, 1081-1088.

6 M. Bohner, J. Lemaitre, H. P. Merkle and B. Gander, J. Pharm. Sci., 2000, 89, 1262-1270.

7 M. Bohner, J. Lemaitre, P. Van Landuyt, P. Zambelli, H. Merkle and B. Gander, J. Pharm. Sci., 1997, 86, 565-572.

8 L. M. Grover, U. Gbureck, A. M. Young, A. J. Wright and J. E. Barralet, J. Mater. Chem., 2005, 15, 4955-4962.

9 Y. Fukase, E. D. Eanes, S. Takagi, L. C. Chow and W. E. Brown, J. Dent. Res., 1990, 69, 1852-1856.

10 E. F. Burguera, H. H. Xu, S. Takagi and L. C. Chow, J. Biomed. Mater. Res., Part A, 2005, 75, 966-975.

11 P. A. Heasman, L. Heasman, F. Stacey and G. I. McCracken, J. Clin. Periodontol., 2001, 28, 90-95.

12 D. Leung, D. A. Spratt, J. Pratten, K. Gulabivala, N. J. Mordan and A. M. Young, Biomaterials, 2005, 26, 7145-7153.

13 M. Wilson, H. Patel and J. Fletcher, Oral Microbiol. Immunol., 1996, 11, 188-192.

14 K. Schwach-Abdellaouia, N. Vivien-Castionib and R. Gurny, Eur. J. Pharm. Biopharm., 2000, 50, 83-99.

15 A. Young, A. Sherpa, G. Pearson, B. Schotlander and D. N. Waters, Biomaterials, 2000, 21, 1971-1979.

16 A. M. Young, S. A. Rafeeka and J. A. Howlett, Biomaterials, 2004, 25, 823-833.

17 A. O. Majekodunmi and S. Deb, J. Mater. Sci.: Mater. Med., 2003, 14, 747-752.

18 A. A. Mirtchi and J. Lemaitre, Biomaterials, 1989, 10, 475-480.

19 U. Gbureck, O. Grolms, J. E. Barralet, L. M. Grover and R. Thull, Biomaterials, 2003, 24, 4123-4131.

20 M. P. Hofmann, S. N. Nazhat, U. Gbureck and J. E. Barralet, J. Biomed. Mater. Res., Part B, 2006, 79, 360-364.

21 S. K. Timonshenko, Theory of Plates and Shells, McGraw Hill Higher Education, 1964.

22 A. Akinmade and J. Nicholson, J. Mater. Sci.: Mater. Med., 1995, 6, 483-485.

23 E. Charrière, S. Terrazzoni, C. Pittet, P. Mordasini, M. Dutoit, J. Lemam and P. Zysset, Biomaterials, 2001, 22, 2937-2945.

24 J. B. Quinn and G. D. Quinn, Dent. Biomater., 2010, 26, 135-147.

25 F. Tamimi, Z. Sheikh and J. Barralet, Acta Biomater., 2012, 8, 474-487.

26 M. P. Hofmann, A. R. Mohammed, Y. Perrie, U. Gbureck and J. E. Barralet, Acta Biomater., 2009, 5, 43-49.

27 N. A. Peppas, J. Biomed. Mater. Res., 1983, 17, 1079-1087.

28 P. Frayssinet, L. Gineste, P. Conte, J. Fages and N. Rouquet, Biomaterials, 1998, 19, 971-977.

29 L. Grover, J. Knowles, G. Fleming and J. Barralet, Biomaterials, 2003, 24, 4133-4141.

30 B. R. Constantz, B. M. Barr, I. C. Ison, M. T. Fulmer, J. Baker, L. McKinney, S. B. Goodman, S. Gunasekaren, D. C. Delaney, J. Ross and R. D. Poser, J. Biomed. Mater. Res., 1998, 43, 451461.

31 J. L. Giocondi, B. S. El-Dasher, G. H. Nancollas and C. A. Orme, Philos. Trans. R. Soc., A, 2010, 368, 1937-1961.

32 E. A. Abou Neel, V. Salih, P. A. Revell and A. M. Young, Adv. Eng. Mater., DOI: 10.1002/adem.201300218.

33 P. V. Giannoudis, H. Dinopoulos and E. Tsiridis, Injury, 2005, 36(suppl. 3), S20-S27. 